\title{
Evaluation of tensile Bond Strength of dentin adhesive on dentin- Resin interface: An in-vitro study
}

\author{
Dr. Keyur P. Chande ${ }^{1,}$ Dr. Narendra U. Manwar ${ }^{2,}$ Dr. Manoj G. Chandak ${ }^{3}$ \\ ${ }^{1}$ (Post-Graduate Student,Dept. Of Conservative Dentistry And Endodontics Sharad Pawar Dental \\ College,Datta Meghe Institue Of Medical Sciences (Du).Wardha, India) \\ ${ }^{2}$ (Professor ,Dept. Of Conservative Dentistry And Endodontics Sharad Pawar Dental College,Datta Meghe \\ Institue Of Medical Sciences (Du).Wardha, India) \\ ${ }^{3}$ (Professor, Dept. Of Conservative Dentistry And Endodontics Sharad Pawar Dental College,Datta Meghe \\ Institue Of Medical Sciences (Du).Wardha, India)
}

\begin{abstract}
AIM: The Aim of this study is to compare the effect of surface moisture on dentinal tensile bond strength

MATERIAL/METHOD:Sixty freshly extracted caries free Mandibular first molars were selected. The specimens were randomly divided into three groups of 20 teeth each. Occlusal surface were ground by diamond disc till all occlusal enamel is removed. After treating the occlusal surface of specimens with $37 \%$ orthophosphoric acid for $15 \mathrm{sec}$,specimens were divided into 3 groups namely. Group I (Blot Dry), Group II ( One Second Dry) and Group III (Over Dry). Each group was treated with single bond adhesive(3M ESPE). Composite cylinders were build up using Teflon moulds and cured. Tensile bond strength was tested using INSTRON universal testing machine.The results were analysed statistically.

RESULT: The tensile bond strength values were highest in group I(Blot dry) and statistically significant CONCLUSION: Blot drying after etching provided better bond strength.

Keywords: Blot dry, dentin, surface moisture
\end{abstract}

\section{Introduction}

In 1955, Buonocore proposed that acid etchants could be used to alter the enamel surface and make it more receptive to adhesion. On the other hand, dentinal adhesion has proved to be more difficult and less predictable. Much of the difficulty in bonding to dentin results from its structure, which is morphologically heterogeneous and physiologically dynamic.

The histological characterization of dentin shows that it is an inhomogenous tissue as it is composed of two kinds of dentin namely, the intertubular dentin and peritubular dentins, with different mineral content. The latter varies also in relation to dentin location. In consequence, the acid etching affects differently the superficial and deep dentin. Deep dentin is more rapidly and more deeply etched than superficial one and a more hydrated substrate is obtained. These factors introduce more variables into the dentin adhesion, which must be taken into account. $^{2}$

Manufacturers of dentinal bonding systems today almost universally indicate that dentinal dryness is critical for the proper functioning of their products. But vital dentin is inherently wet and thorough desiccation is very difficult to achieve clinically. Studies simulating physiologic conditions indicate that dentinal bond strengths are frequently diminished in the presence of dentinal wetness. ${ }^{3}$

Adhesive systems have undergone a great evolution with major improvements in dentinal bonding occurring when hydrophilic monomers and organic solvents were added to primers and adhesives, enabling their use on a moist dentin substrate. ${ }^{4}$

When these adhesive systems are applied on conditioned dentin hybrid layer composed of collagen fibrils and residual hydroxyapatite crystallites encased in resin is formed. The hybrid layer recovers much of the resistance and rigidity of the original mineralized dentin, and it is the main bonding mechanism of most current dentin adhesive systems. ${ }^{5}$

Bonding to dentin is achieved due to primer and adhesive penetration into demineralized dentin forming the hybrid layer. ${ }^{6}$ This layer may result from different systems and bonding techniques. Etch-and-rinse adhesive systems remove the smear layer completely and expose the collagen fibrils while for self-etching primers the smear layer is not completely removed but incorporated into the hybrid layer. ${ }^{7}$

Many of the current generation of dentin adhesives depend on the permeation of hydrophilic resin into chemically conditioned dentin. ${ }^{8}$

It has been reported that as long as the dentin is kept fully hydrated, the surface morphology of the demineralized layer does not change, i.e., the water supporting the collagen matrix is not lost, and the matrix network does not shrink. ${ }^{9}$ 
Hence this in-vitro study was carried out with the aim to evaluate the effect of surface moisture on dentinal tensile bond strength to dentin adhesive.

\section{Material And Method}

Sixty freshly extracted caries free Mandibular first molars were selected. The specimens were randomly divided into three groups of 20 teeth each. Occlusal surface were ground by diamond disc till all occlusal enamel is removed. The teeth were embedded into the self cure acrylic resin coated with nail polish of different colors for each group leaving the dentine surface exposed.

After treating the occlusal surface of specimens with $37 \%$ orthophosphoric acid for $15 \mathrm{sec}$,specimens were divided into 3 groups namely.

Group I ( Blot Dry), Group II ( One Second Dry) and Group III ( Over Dry).

Group I - Blot Dry: The excess water was blotted with tissue paper maintaining a moist dentine surface

Group II - One Second Dry: The etched dentine surface was air dried for 1 second using an oil free air source (Hair drier) from a distance of $10 \mathrm{~cm}$.

Group III- Over Dry: The etched dentine surface was air dried for 30 seconds using compressed oil free air source (Hair drier) from a distance of $10 \mathrm{~cm}$.

Single bond adhesive (3M) was applied to the demineralized dentine using a fully saturated brush tip of adhesive for each coat, two consecutive coats were applied and then gently air dried for 2-5 sec and light cured for $10 \mathrm{sec}$.

The composite resin was condensed to $2 \mathrm{~mm}$ thickness in a hollow poly vinyl cylinder and light cured for 40 sec. Another composite resin of $2 \mathrm{~mm}$ thickness was placed over the first placed composite increment.

A 26 gauge ligature wire was twisted at one end and a loop was formed at another end. Twisted end was placed inside the $2 \mathrm{~mm}$ of uncured composite resin.

After complete curing poly vinyl cylinder moulds were cut and removed, leaving the $4 \mathrm{~mm}$ of resin with ligature wire bonded to dentine. All the specimens were immersed in water for $24 \mathrm{hr}$.

Tensile bond strength was then measured using an Instron universal testing machine with a cross head speed of $1.5 \mathrm{~mm}$ per min.(Universal testing machine (computerized, software based) Company: Star Testing System, India. Model No. STS 248

\section{Results}

Results were subjected to statistical analysis (Kruskal Wallis one way ANOVA) and comparison between the groups was done by tukey post-hoc The mean tensile bond strength values of group I ( $8.36 \pm 3.34$ )was the highest and was statistically significant, with group II and III . Group I showed slightly higher values than group II (6.92 \pm 2.53$)$.

The mean tensile bond strength and standard deviation are presented in table 1.

Table 2 shows statistical analysis of difference between the tensile bond strength between different groups . It was statistically significant between Group I, Group II and Group III .

\section{Discussion}

The advent of resin composite restorative material has brought about a revolution in the field of restorative dentistry. Adhesion of restorative material to tooth structure becomes a routine and reliable aspect of modern dentistry. Strong durable bonds between dental biomaterials and tooth structures are essential not only from a mechanical point of view, but also from biologic and esthetic consideration. The key element for adhesion is the intimate bond that develops between the adhesive and the substrate. As there is little evidence to suggest that dentin-bonding agents bond chemically to dentin, current approaches appear to depend on its effective penetration of partially demineralized dentin and intratubular dentin. ${ }^{10,11}$

Resin tag formation can contribute to the overall bond strength in several different ways. The interaction of tissues and biomaterials at biological interfaces is extremely important, but it is very difficult to connect natural tissue with artificial material.

Due to the difference in orientation of the dentinal tubules toward the pulp, in many instances the penetration of resin into the dentinal tubules may generate mechanical retention simply because the resin tags penetrate into dentin from different directions, providing nonparallel retention.

Once this occurs, there will be no possible path of removal unless some of the tags fracture. Resin tags are also able to firmly bond to the tubule walls, thereby increasing both retention and seal. ${ }^{12}$ The seal helps reduce the increased risk of dentinal sensitivity and pulpal irritation that can occur due to leakage of bacterial products. 
The next major contribution to dentin bonding is the formation of a hybrid layer. The resin infiltrated demineralized intertubular dentin, which is a hybrid of dentin and resin, is called the hybrid layer. This layer was first reported in 1982 by Nakabayashi and coworkers. ${ }^{13}$ As mentioned, the diffusion of monomer into the substrate and its subsequent polymerization results in the molecular entanglement of the polymer chains with collagen fibrils, which helps in retention. The hybrid layer not only promotes good bond strength, but also behaves like an impermeable membrane that can prevent noxious stimuli from invading pulpal tissue through the dentinal tubules. Hybridized dentin reduces the risk of microleakage, incidence of secondary caries, and post-operative sensitivity.

Acid etching of dentin removes the mineral phase and increases the porosities of these tissues enormously. In superficial dentin, the surface of dentin changes from one in which only $1 \%$ of surface area is porous (the porosity results from the presence of dentinal tubules) before etching, to a condition in which $13.4 \%$ of the surface area consists of water-filled tubules that can serve as avenues for the infiltration of suitable monomers. Kimochi et al, in 1999 suggested that 37\% phosphoric acid to be used in order to attain high tensile bond strength. ${ }^{14}$

Thomas Pioch et al, in 1998 had observed that the highest tensile bond strengths were achieved after 15 's of etching compared to 30 's and 60 's of etching. ${ }^{15}$

Kanca and Gwinnett suggested that resin primer solvents such as ethanol or acetone aided in the displacement of surface moisture, thus carrying the dissolved resin into the patent dentinal tubules and the demineralized intertubular dentin following acid conditioning. The rationale of wet or moist bonding is to prevent the collagen network exposed by acid etching from collapsing. ${ }^{4}$

Collapse of collagen fibrils occurs when the conditioned dentin surface is dried, thereby inhibiting infiltration of most current monomers into dentine.

The wet bonding technique can promote efficient resin monomer diffusion into the demineralized matrix only if excess water on the dentin surface is eliminated with the dry cotton after etching, water rinsing, and then replaced by monomers during the subsequent step. In the currently available adhesive systems, hydrophilic primer monomers are dissolved in volatile solvents, such as acetone and ethanol, that aid in displacement of the remaining water and also carrying the polymerizable hydrophilic monomers into the opened dentinal tubules and through the nano-spaces of the collagen web. ${ }^{14}$

According to Tay et al, the presence of excess water dilutes the primer and its components into different phases. This leads to the formation of water blisters and micelles.

Air drying for $1 \mathrm{sec}$ resulted in partial collapse of the demineralized collagen matrices. However, since an ethanol- based adhesive invariably contains a small amount of water, this extrinsic water together with the increase in intrinsic moisture caused by removal of the smear layer could have resulted in rehydration of the partially collapsed collagen matrix during the $10 \mathrm{sec}$ of adhesive application. ${ }^{15}$

Y Nakaoki et al (2002) investigated the effects of wet and dry conditions of phosphoric acid etched dentin on resin bonding and determined the optimum moisture condition for resin bonding using an ethanolbased one-bottle adhesive system. In the one-second dry group, the moisture content of the collagen network was possibly too low, such that hybrid layer formation was not as good even though the bond strength was high. ${ }^{16}$

ThumuJayaprakash et.al (2010) evaluated the effect of surface moisture on dentinal tensile bond strength. After acid etching and rinsing blot drying provided consistently better bond strength. In blot drying, after etching and blotting most of the water in the interfibrillar spaces remained to support the collagen network. During application of the adhesive, the ethanol solvent could drive water away sufficiently to allow penetration of the monomers. ${ }^{17}$

Thus, the monomers infiltrated into the demineralized dentin, polymerize and produce a hybrid layer without collapse of the collagen network or separation of the resin from the dentin

When the dentine surface is dried, there is no water to chase and the wetting of the surface is diminished. The addition of alcohol to water decreases the surface tension of water, yet the bond strength generated was not as high as with the acetone solvent.

This is evidently a consequence of alcohol having greater hydrogen bonding than acetone and thus it does not chase water as effectively. Again when the surface is dry, there is no interaction of the solvent with water and adhesion is diminished. (Nakajima M et.al 2000). ${ }^{18}$

\section{Conclusion:}

Result of the present study suggest that Blot drying with tissue paper was having highest statistically bond strength as compared to over dry and one second dry.

This study opens perspectives for future researchers to standardize the amount of moisture present on dentine immediately prior to bonding that may lead to a better understanding of the effects of varying degrees of moisture on the performance of bonding agents. 


\section{References:}

[1]. Brudevold F, Buonocore M, Wileman W. A report on a resin composition capable of bonding to human dentin surfaces. J Dent Res. 1956;35:846-51

[2]. Marshall GW,Marshall SJ ,Kinney JH, Balloch M. The dentin substrate structure and properties related to bonding .J Dent 1997:25; 441-58

[3]. Andraetis S, Koth D, Bayne S. Effect of dentin hydrostatic pressure on bond strengths to dentin, / Dcnl Res 1988;67:363

[4]. Gwinnett J. Moist versus dry dentin: Its effects on shear bond strength. Am J Dent 1992;5:127-129.

[5]. Pashley DH, Ciucchi B, Sano H, Horner JA. Permeability of dentin to adhesive agents. Quintessence Int 1993; 24:618-631.

[6]. Nakabayashi N, Saimi Y. Bonding to intact dentin. J Dent Res 1996;75:1706-1715.

[7]. Yoshiyama M, Matsuo T, Ebisu S, Pashley D. Regional bond strengths of self-etching/self-priming adhesive systems. J Dent 1998;26:609-616

[8]. Eick JD, Robinson, SJ, Chappell RP, Cobb CM, Spencer P (1993). The dentinal surface: Its influence on dentinal adhesion. Part III. Quintessence Int 24:571-582.

[9]. Kinney JH, Balooch M, Marshall GW, Marshall SJ. Atomicforce microscopic study of dimensional changes in human dentine during drying. Arch Oral Biol 1993;38: 1003-1007.

[10]. Farid Mohammed Sabry,El-Askary,Mohammed Aalah AbdelazizNassif, Andrea Andrade,AlessandraReis,AlessandroDouradoLoguercio. Effect of surface area and air-drying distance on shear bond strength of etch-and-rinse adhesive. Braz Oral Res., (São Paulo) 2012Sep-Oct;26(5):418-23.

[11]. Melissa aline de silva, Patricia rangel, Daphne barcellos, Clovis pagani, carlosgomestorres. Bond strength of adhesive systems with different solvents to wet and dry dentin (2013) J Contemp Dent Pract, Jan-Feb 2013;14(1):9-13

[12]. Nakabayashi N, Pashley DH (eds). Hybridization of Dental Hard Tissues. Chicago: Quintessence, $1998: 37-45$.

[13]. Pashley DH, RM Carvalho. Dentin permeability and dentine adhesion. J Dent Res 1997;25:355-372.

[14]. Neme AL, Maxson BB, Pink FE, Aksu MN. Microleakage of Class II packable resin composites lined with flowables: an in-vitro study. Operative Dentistry 2002; 27 (6): 600-5.

[15]. Tay FR, Gwinnett AJ, Wei SH. The overwet phenomenon: An optical, micro morphological study of surface moisture in the acidconditioned resin-dentin interface. Am J Dent. 1996;9:43-8

[16]. Nakaoki Y, Nikaido T, Burrow MF, Tagami J. Effect of residual water on dentin bond strength and hybridization of a one-bottle adhesive system.Oper Dent. 2002 Nov-Dec;27(6):563-8.

[17]. ThumuJayaprakash, M R Srinivasan, and R Indira Evaluation of the effect of surface moisture on dentinal tensile bond strength to dentine adhesive: An in-vitro study J Conserv Dent. 2010 Jul-Sep; 13(3): 116-118.

[18]. Nakajima M, Kanemura N, Pereira PN, Tagami J, Pashley DH. Comparative micro tensile bond strength and SEM analysis of bonding to wet and dry dentin. Am J Dent. 2000;13:324-8

\section{TABLES}

TABLE: 1 Comparison of Mean Tensile Bond Strength in four groups

\begin{tabular}{|c|c|c|c|c|c|c|c|c|}
\hline \multirow{2}{*}{ Group } & \multirow{2}{*}{$\mathrm{N}$} & \multirow{2}{*}{ Mean } & \multirow{2}{*}{$\begin{array}{c}\text { Std. } \\
\text { Deviation }\end{array}$} & \multirow{2}{*}{$\begin{array}{l}\text { Std. } \\
\text { Error }\end{array}$} & \multicolumn{2}{|c|}{$\begin{array}{l}95 \% \text { Confidence } \\
\text { Interval for Mean }\end{array}$} & \multirow{2}{*}{ Minimum } & \multirow{2}{*}{ Maximum } \\
\hline & & & & & $\begin{array}{l}\text { Lower } \\
\text { Bound }\end{array}$ & $\begin{array}{l}\text { Upper } \\
\text { Bound }\end{array}$ & & \\
\hline Group I & 20 & 8.36 & 3.34 & 0.74 & 6.79 & 9.92 & 3.86 & 14.39 \\
\hline Group II & 20 & 6.92 & 2.53 & 0.56 & 5.73 & 8.11 & 0.74 & 9.81 \\
\hline Group III & 20 & 5.57 & 2.92 & 0.65 & 4.20 & 6.94 & 2.12 & 12.19 \\
\hline Total & 60 & 6.14 & 3.16 & 0.35 & 5.44 & 6.85 & 0.50 & 14.39 \\
\hline
\end{tabular}

TABLE: 2

\section{Comparison of Tensile Bond Strength in four groups by One way ANOVA}

\begin{tabular}{|c|c|c|c|c|c|} 
Source of variation & $\begin{array}{c}\text { Sum of } \\
\text { Squares }\end{array}$ & df & Mean Square & F & p-value \\
\cline { 1 - 3 } Between Groups & 233.94 & 3 & 77.98 & \multirow{2}{*}{10.59} & 0.000 \\
\cline { 1 - 3 } Within Groups & 559.19 & 76 & 7.35 & & \\
\cline { 1 - 4 } Total & 793.13 & 79 & & \\
\hline
\end{tabular}

\section{Authors:}

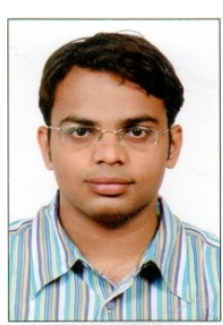

\section{Dr. Keyur P. Chande *}

Post-Graduate Student Dept. Of Conservative Dentistry And Endodontics Sharad Pawar Dental College Datta Meghe Institue Of Medical Sciences (Du) Wardha , India-442004 


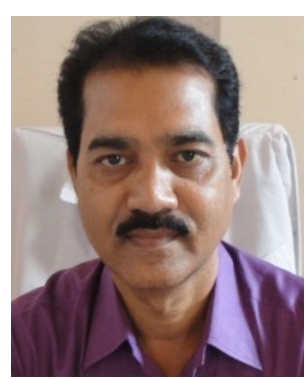

Dr. Narendra U. Manwar**

Professor Dept. Of Conservative Dentistry And Endodontics Sharad Pawar Dental

College Datta Meghe Institue Of Medical Sciences (Du) Wardha , India-442004

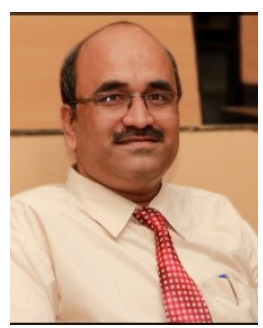

Dr. Manoj G. Chandak***

Professor Dept. Of Conservative Dentistry And Endodontics Sharad Pawar Dental College

Datta Meghe Institue Of Medical Sciences (Du) Wardha, India442004 